\title{
The Properties of the Water-Soluble Hydroxy-Polyhydroxy fullerenes in Auto-Oxidation Reactions Epinephrine
}

\author{
Olga A. Yaykova ${ }^{a}$, Felix N. Tomilina, \\ Irina A. Dubinina ${ }^{\mathrm{a}, \mathrm{b}}$, Alexander A. Kuzubov, \\ Alexander I. Dudnik ${ }^{\mathrm{a}, \mathrm{b}}$, Natalia G. Vnukova ${ }^{\mathrm{a}, \mathrm{b}}$, \\ Sergey G. Ovchinnikov ${ }^{\mathrm{a}, \mathrm{b}}$ and Grigory N. Churilov ${ }^{\mathrm{a}, \mathrm{b}}$ \\ ${ }^{a}$ Institute of Physics. LV Kirensky SB RAS \\ Akademgorodok, Krasnoyarsk, 660036, Russia \\ ${ }^{b}$ Siberian Federal University \\ 79 Svobodny, Krasnoyarsk, 660041, Russia
}

Received 16.09.2015, received in revised form 03.10.2015, accepted 22.11.2015

The studied of the influence of fullerenoles on adrenaline auto-oxidation reaction by optical and theoretical methods was carried out in this work. It was shown that fullerenols at concentrations from $0.0005 \mathrm{mg} / \mathrm{ml}$ to $0.5 \mathrm{mg} / \mathrm{ml}$ exhibits prooxidant activity and accelerates autoxidation reaction of adrenaline. The suggested scheme of auto-oxidation reaction, which explained by energy advantage under transferring electron from the molecule of adrenaline to fullerenol by density functional method B3LYP/6-31(p,d).

Keywords: fullerenoles, adrenaline, prooxidant activity, optical density, B3LYP.

DOI: $10.17516 / 1998-2836-2015-8-4-533-540$.

(C) Siberian Federal University. All rights reserved

* Corresponding author E-mail address: felixnt@gmail.com 


\section{Свойства водорастворимых \\ окси-полигидрокси фуллеренов \\ в реакции автоокисления адреналина}

О.А. Яйкова ${ }^{\mathrm{a}}$, Ф.Н. Томилин ${ }^{\mathrm{a}, \boldsymbol{\sigma}}$, И.А. Дубинина ${ }^{\mathrm{a}, \boldsymbol{\sigma}}$, А.А. Кузубов ${ }^{\mathrm{a}}$, А.И. Дудник ${ }^{\mathrm{a}, \boldsymbol{\sigma}}$, Н.Г. Внукова ${ }^{\mathrm{a}, \boldsymbol{\sigma}}$, С.Г. Овчинников ${ }^{\mathrm{a}, \boldsymbol{\sigma}}$, Г.Н. Чурилов ${ }^{\mathrm{a}, \bar{\sigma}}$ ${ }^{a}$ Сибирский федеральный университет Россия, 660041, Красноярск, пр. Свободный, 79 ${ }^{6}$ Институт физики им. Л.В. Киренского СО РАН Россия, 660036, Красноярск, Академгородок

В данной работе проведено исследование влияния фуллеренолов на реакцию автоокисления адреналина с помощью оптических и теоретических методов. Показано, что фуллеренол в концентрациях от 0,0005 до 0,5 мг/мл проявляет прооксидантную активность и ускоряет реакиию автоокисления адреналина. С помощью метода функиионала плотности B3LYP/631(p,d) представлена предполагаемая схема реакиии автоокисления, которая объясняется энергетической выгодой при переносе электрона с молекуль адреналина на молекулу фуллеренола.

Ключевые слова: фуллеренол, адреналин, прооксидантная активность, оптическая плотность, метод функиионала плотности B3LYP.

\section{Введение}

В настоящее время известно, что область применения фуллеренов и фуллереновых производных огромна: от защиты клеток $[1,2]$ до транспортировки лекарств [3]. Фуллерен способен взаимодействовать со свободными радикалами, но имеет низкую биосовместимость, поэтому его необходимо предварительно химически модифицировать. Гидроксилированные фуллерены - фуллеренолы - демонстрируют не только хорошую растворимость в воде, но и, в зависимости от концентрации, антиоксидантную и прооксидантную активность и являются перспективными объектами для создания лекарственных препаратов для лечения нейродегенеративных заболеваний [4]. Исследованиями биологической активности фуллеренолов с различным числом гидроксильных групп $\left(\mathrm{C}_{60}(\mathrm{OH})_{12-14}, \mathrm{C}_{60}(\mathrm{OH})_{18-24}, \mathrm{C}_{60}(\mathrm{OH})_{30-38}\right)$ установлено, что растворимость фуллеренолов коррелирует с числом гидроксильных групп, фуллеренолы $\mathrm{C}_{60}(\mathrm{OH})_{18-24}$ и $\mathrm{C}_{60}(\mathrm{OH})_{30-38}$ не оказывают токсического эффекта на клеточные культуры, а фуллеренол $\mathrm{C}_{60}(\mathrm{OH})_{18-24}$ проявляет максимальную биологическую активность $[5,6]$.

Обнаружено, что фуллеренол $\mathrm{C}_{60}$ проявляет антиоксидантную активность и способен утилизировать почти все активные формы кислорода и азота [7, 8], а также при значительных концентрациях $\mathrm{C}_{60}$ фуллеренол показывает прооксидантную активность и сам служит источником активных частиц. 
Olga A. Yaykova, Felix N. Tomilin... The Properties of the Water-Soluble Hydroxy-Polyhydroxy fullerenes...

При синтезе фуллеренола может быть получено большое количество изомеров и молекул с разным количеством гидроксильных и карбонильных групп и, соответственно, с разной растворимостью и биофункциональностью. В этой статье мы рассматриваем стабильность самых широко используемых фуллеренолов вида $\mathrm{C}_{60} \mathrm{OH}_{\mathrm{n}} \mathrm{O}_{2}(\mathrm{n}=24,36,48)$ и электронные свойства фуллеренола с наибольшей биологической активностью $-\mathrm{C}_{60}(\mathrm{OH})_{24} \mathrm{O}_{2}-$ в реакции с адреналином. Также приводим результаты экспериментального исследования оксидантной активности фуллеренола $\mathrm{C}_{60}$ в реакции автоокисления адреналина.

\section{Материалы и методы}

Фуллереновую смесь синтезировали методом электродугового распыления графита [9] и методом ВЭЖХ выделили фракцию чистого (99 \%) $\mathrm{C}_{60}$. Гидроксилирование проводили прямым окислением азотной кислотой и последующим гидролизом. Антиоксидантную активность определяли по известной методике, которая была разработана для водных экстрактов растительного сырья и впервые применена для водных растворов фуллеренов общей формулы $\mathrm{C}_{60}(\mathrm{OH})_{\mathrm{x}} \mathrm{O}_{\text {y }}[10]$. Накопление окисленных продуктов адреналина путем определения оптической плотности измеряли через 7 мин после начала реакции на спектрофотометре UV 1700 (Shimadzu) при длине волны 348 нм. Реакция автоокисления адреналина в карбонатном буфере $(\mathrm{pH}=10,65)$ при комнатной температуре была использована в качестве контрольной пробы.

Квантово-химические расчеты характеристик фуллеренолов осуществляли с помощью метода функционала плотности B3LYP [11, 12] в базисе 6-31(p,d) программы GAMESS [13]. Предварительно для ускорения расчётов геометрию молекул оптимизировали с помощью полуэмпирического метода РМ7 программы МОРАС2012 [14].

\section{Результаты и обсуждение}

В работе проведено исследование влияния фуллеренолов на реакцию автоокисления адреналина. На рис. 1 представлены результаты экспериментального исследования оксидантной активности фуллеренола $\mathrm{C}_{60}(\mathrm{OH})_{24}$. Использованы четыре различные концентрации фуллеренола: $\mathrm{C} 1=0,0005$ мг/мл, $\mathrm{C} 2=0,005$ мг/мл, C3=0,05 мг/мл и C4=0,5 мг/мл. Как видно из диаграммы, увеличение концентрации фуллеренола вызывает увеличение оптической плотности раствора, что обусловлено увеличением накопления продуктов окисления адреналина. Таким образом, фуллеренол в указанных концентрациях проявляет прооксидантную активность и ускоряет реакцию автоокисления адреналина.

Для проверки эксперимента были проведены квантово-химические расчёты всех предполагаемых участников реакции автоокисления. В качестве объектов были выбраны фуллеренолы с двумя атомами кислорода и 24, 36, 48 группами ОН. В настоящее время не установлено, какой конкретно изомер или группу изомеров получают в ходе синтеза. В работе [15] рассчитаны различные изомеры и показано, что экспериментально трудно отдать предпочтение какомулибо изомеру, так как они мало отличаются по своим свойствам. Поэтому в работе рассмотрены три крайних случая (рис. 2). Были построены изомеры фуллеренола таким образом, чтобы ОН-группы располагались либо на одной полусфере фуллерена, либо на двух противоположных сторонах, либо равномерно по сфере. Атомы кислорода старались располагать максимально далеко друг от друга и от ОН-групп. На рис. 2 представлены три изомера фуллеренола с 24 


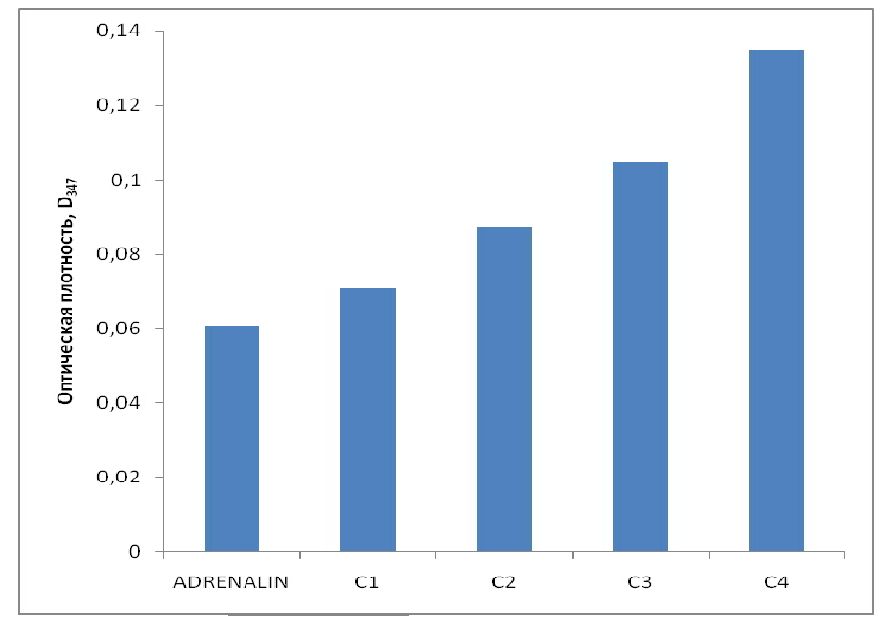

Рис. 1. Гистограмма зависимости оптической плотности раствора адреналина в зависимости от концентрации фуллеренола $\mathrm{C}_{60}$

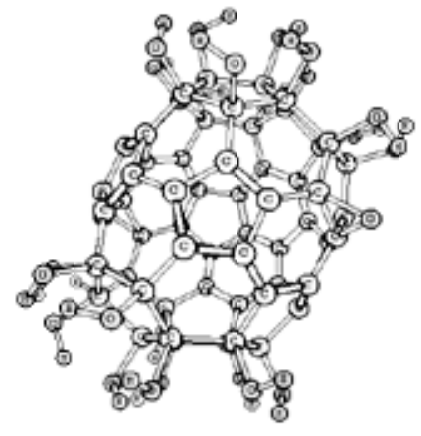

$\mathrm{C}_{60}(\mathrm{OH})_{24} \mathrm{O}_{2}, \mathrm{i} 1$

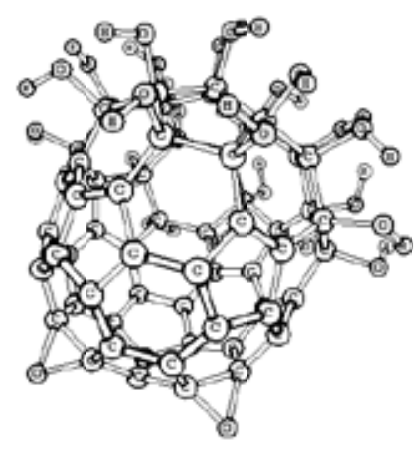

$\mathrm{C}_{60}(\mathrm{OH})_{24} \mathrm{O}_{2}, \mathrm{i} 2$

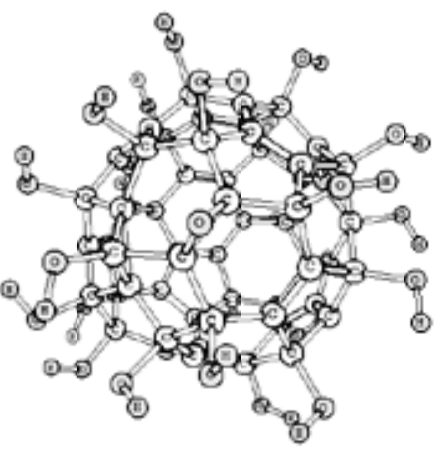

$\mathrm{C}_{60}(\mathrm{OH})_{24} \mathrm{O}_{2}, \mathrm{i} 3$

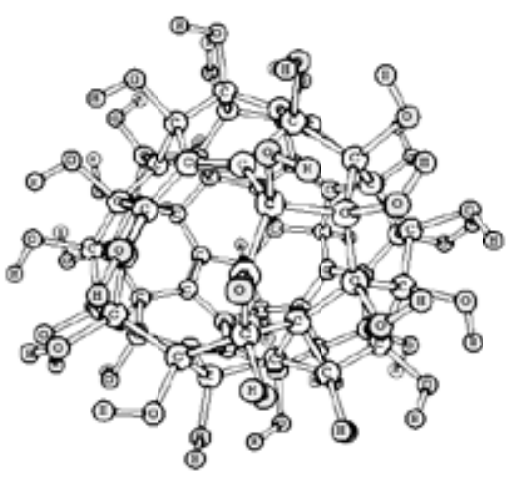

$\mathrm{C}_{60}(\mathrm{OH})_{36} \mathrm{O}_{2}, \mathrm{i} 3$

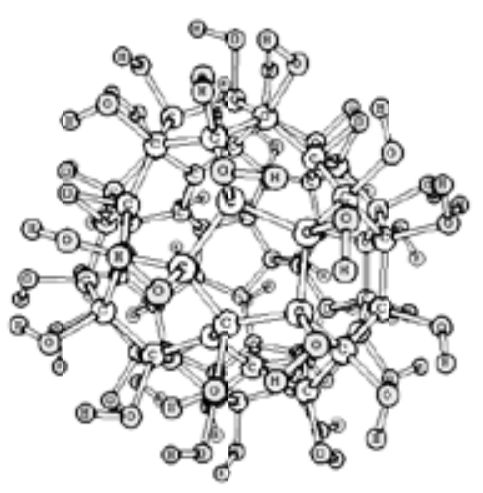

$\mathrm{C}_{60}(\mathrm{OH})_{48} \mathrm{O}_{2}, \mathrm{i} 3$

Рис. 2. Фуллеренолы общей формулы $\mathrm{C}_{60}(\mathrm{OH})_{24} \mathrm{O}_{2}$ с различным расположением ОН- и О-групп по сфере фуллерена $\mathrm{C}_{60}$ и фуллеренолы с разным количеством ОН-групп 
ОН-группами и по одному наиболее энергетически выгодному изомеру с 36 и 48 ОН-группами. Наличие гидроксидных групп сильно меняет симметричную форму фуллерена.

В табл. 1 даны энергии верхних занятых молекулярных орбиталей (ВЗМО) и нижних вакантных (НBMO) орбиталей. Из таблицы видно, что изомер і3 имеет самую маленькую энергетическую щель между ВЗМО и НВМО, что говорит о большей по сравнению с изомерами i1 и i2 химической активности.

Согласно химической структуре и, соответственно, своим свойствам адреналин является донором электронов, и эта его функция реализуется именно в процессе хиноидного окисления [16]. Молекула адреналина была рассчитана в двух формах - нейтральной и с зарядом $-1 e^{-}$(рис. 3). Рассчитывались различные конформеры адреналина, отличающиеся расположением водорода в ОН-группах. Энергетическая разница между конформерами составила не более 10 кДж/моль. В дальнейшем приведены данные для энергетически эффективного конформера. Также для анализа реакции была рассчитана молекула кислорода в триплетном состоянии.

В итоге все расчётные данные для анализа реакции каталитического окисления адреналина и получение анион-радикала молекулы кислорода в присутствии молекул фуллеренолов представлены на рис. 4. На рисунке приведены энергии ВЗМО и НВМО орбиталей трех изомеров фуллеренола с двадцатью четырьмя группами ОН в синглетном состоянии, фуллеренол с зарядом - $1 e^{-}$в дублетном состоянии, адреналин, адренолинполухинон с зарядом $-1 e^{-}$и молекула кислорода в триплетном состоянии соответственно.

В присутствии фуллеренолов, по нашему мнению, реакция идёт по пути А. Разница между уровнями ВЗМО адреналина и НВМО фуллеренола составляет 1,35 эВ в отличие от ВЗМО и НВМО адреналина, где энергетическая щель равна 5,70 эВ. Очевидно, что требуются замет-

Таблица 1. Энергии ВЗМО и НВМО изомеров фуллеренола

\begin{tabular}{|c|c|c|c|c|c|}
\hline \multirow{2}{*}{$\begin{array}{c}\text { Характеристика } \\
\text { MO }\end{array}$} & \multicolumn{3}{|c|}{ Изомеры $\mathrm{C}_{60}(\mathrm{OH})_{24} \mathrm{O}_{2}$} & \multicolumn{2}{|c|}{$\begin{array}{c}\text { Изомеры i3 других } \\
\text { фуллеренолов }\end{array}$} \\
\hline & $\mathrm{C}_{60}(\mathrm{OH})_{24} \mathrm{O}_{2}, \mathrm{il}$ & $\mathrm{C}_{60}(\mathrm{OH})_{24} \mathrm{O}_{2}, \mathrm{i} 2$ & $\mathrm{C}_{60}(\mathrm{OH})_{24} \mathrm{O}_{2}, \mathrm{i} 3$ & $\mathrm{C}_{60}(\mathrm{OH})_{36} \mathrm{O}_{2}, \mathrm{i} 3$ & $\mathrm{C}_{60}(\mathrm{OH})_{48} \mathrm{O}_{2}, \mathrm{i} 3$ \\
\hline E (HBMO),эВ & $-3,50$ & $-3,68$ & $-4,17$ & $-3,13$ & $-3,48$ \\
\hline E (B3MO), эВ & $-5,06$ & $-5,32$ & $-5,01$ & $-4,96$ & $-6,20$ \\
\hline $\begin{array}{l}\Delta \mathrm{E}(\mathrm{B} 3 \mathrm{MO}-\mathrm{HBMO}), \\
\text { эВ }\end{array}$ & 1,56 & 1,64 & 0,83 & 1,83 & 2,42 \\
\hline
\end{tabular}

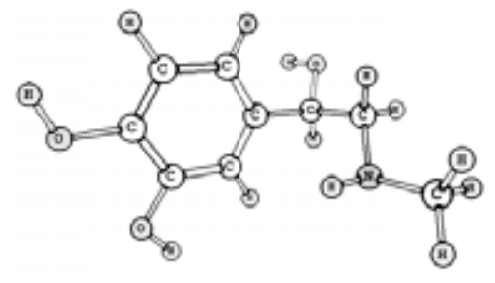

Адреналин

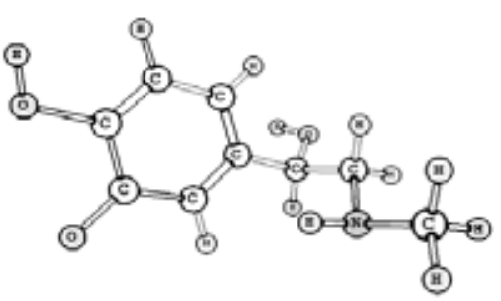

Адреналинполухинон

Рис. 3. Геометрия нейтральной и анионной полухинонной формы молекулы адреналина 


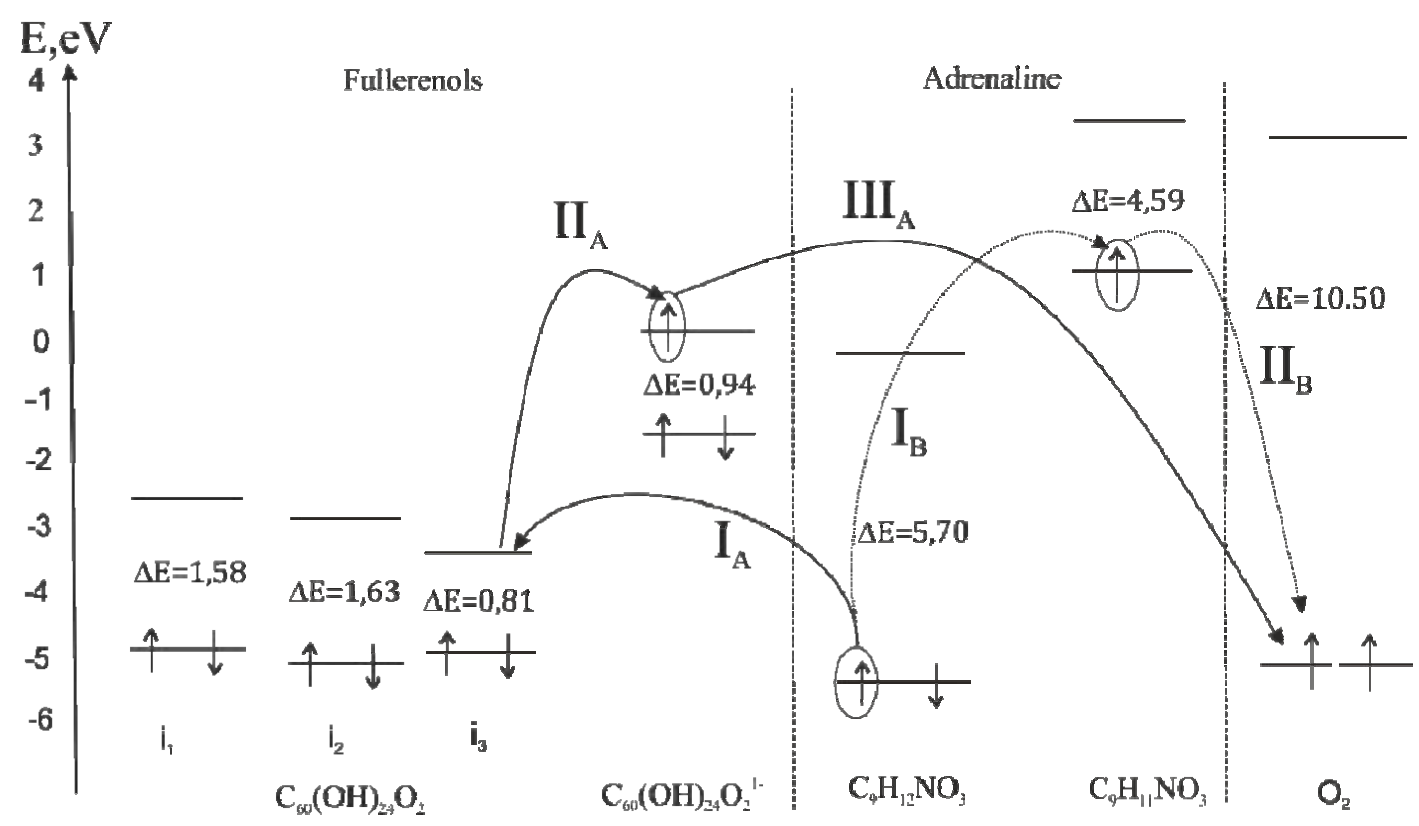

Рис. 4. Схема реакции окисления адреналина: А - реакция с участием фуллеренола; В - без фуллеренола

но более мягкие условия для реализации данного пути. Фуллеренол с зарядом -1 становится энергетически невыгодным по сравнению с нейтральным и будет возвращаться в исходное состояние. Всё это создаёт предпосылки для передачи электрона по двум каналам: или обратно на адреналин, или на кислород, который всегда присутствует в растворе. По схеме видно, что заряженному фуллеренолу выгоднее отдавать электрон на молекулу кислорода и тем самым получить активную форму кислорода. Видно также, что путь В требует больших энергетических затрат по сравнению с путём А. По данному пути система может идти, например, в присутствии основания, когда водород отнимается от адреналина и он переходит в адреналинополухинон.

\section{Выводы}

Расчёты показывают, что фуллеренол может проявлять каталитическую прооксидантную активность и ускорять реакцию автоокисления адреналина. Это объясняется энергетической выгодой при переносе электрона с молекулы адреналина на молекулу фуллеренола. Фуллеренол при этом может служить контейнером электронов и тем самым ускорять реакцию автоокисления.

Работа выполнена при поддержке гранта РФФИ № 15-03-06786.

\section{Список литературы}

1. Foley S., Crowley C., Smaihi M., Bonfils C., Erlanger F.B., Seta P., et al. Cellular localization of a water-soluble fullerene derivatives. Biochem Biophys Res Commun. 2002. Vol. 294, P. 116-119. 
2. Bogdanovic G., Kojic V., Djordjevic A., Canadanovic-Brunet J., Vojinovic-Miloradov M., Baltic V.V. Modulating activity of fullerol $\mathrm{C} 60(\mathrm{OH}) 22$ on doxorubicin-induced cytotoxicity. Toxicol in vitro 2004. Vol. 18, P.629-637.

3. Grebowski J., Krokosz A., Puchala M.. Fullerenol $\mathrm{C} 60(\mathrm{OH}) 36$ could associate to band 3 protein of human erythrocyte membranes. Biochimica et Biophysica Acta (BBA) - Biomembranes 2013. Vol. 1828, № 9, Р. 2007-2014.

4. Xiao L., Takada H., Gan X. H., Miwa N. The wate-soluble fullerene derivative 'Radical Sponge'exerts cytoprotective action against UVA irradiation but not visible-light-catalyzed cytotoxicity in human skin keratinocytes. Bioorg. Med. Chem. Lett. 2006. Vol. 16, P.1590-1595.

5. Eropkin M. Yu., Melenevskaya E. Yu., Nasonova K. V., Bryazzhikova T. S., Eropkina E. M., Danilenko D. M., Kiselev O. I. Synthesis and biological activity of fullerenols with various contents of hydroxyl groups. Pharmaceutical Chemistry Journal 2013. Vol. 47(2), P. 87-91.

6. Гончарова Е. А., Исакова В. Г., Томашевич Е. В., Чурилов Г. Н. Получение водорастворимых полигидроксилированных фуллеренов с использованием наночастиц железа в качестве катализатора. Вестник СибГАУ 2009. Т.22 (1). C. 90-93. [Goncharova E.A., Isakova V.G., Tomashevich E.V., Churilov G.N. Obtaining of water-soluble polyhydroxylated fullerenols with iron nanoparticles as catalyzers. Vestnik of SibGAU 2009. V.22(1), P. 90-93. (In Russ.)]

7. Zhenzhen W., Shukuang W., Zhanghui L., Xingfa G. Syntheses, structures and antioxidant activities of fullerenols: Knowledge Learned at the atomistic level. J Clust Sci .2015. Vol. 26, P. 375388.

8. Yin J.J., Lao F., Fu P.P., Wamer W.G., Zhao Y., Wang P.C., Qiu Y., Sun B., Xing G., Dong J., Liang X.J., Chen C. The scavenging of reactive oxygen species and the potential for cell protection by functionalized fullerene materials. Biomaterials 2009. Vol. 30(4), P. 611-621.

9. Churilov G.N, Kratschmer W, Osipova I.V, Glushenko G.A, Vnukova N.G, Kolonenko A.L, Dudnik A.I. Synthesis of fullerenes in a high-frequency arc plasma under elevated helium pressure. Carbon 2013. Vol.62, P. 389-392.

10. Хасанова С.Р., Плеханова Т.И., Гашимова Э.Х., Галиахметова Э.Х., Клыш Е.А. Сравнительно изучение антиоксидантной активности растительных сборов. Вестник ВГУ. Серия: Химия, Биология, Фармация. 2007. №1. C. 163-166. [Hasanova S.R., Plehanova T.I.,Gashimova D.T.,Galiahmetova E.H., Klysh E.A. Comparative study of antioxidant activity of vegetable gathering. Proc. of Voronezh State University. Series: Chemistry. Biology. Pharmacy. 2007. №1, P. 163-166. (In Russ.)]

11. Lee C., Yang W., Parr R.G. Development of the Colle-Salvetti correlation-energy formula into a functional of the electron density. Phys. Rev. B. 1988. Vol. 37, P. 785-787.

12. Becke A. D. Density-functional exchange-energy approximation with correct asymptotic behavior. Phys. Rev. A 1988. Vol.38, P.3098-3105.

13. Schmidt M. W., Baldridge K. K., Boatz J. A., Elbert S. T., Gordon, M. S.; Jensen, J. H.; Koseki, S.; Matsunaga, N.; Nguyen, K. A.; Su, S.; Windus, T. L.; Dupuis, M.; Montgomery J. A. General Atomic and Molecular Electronic Structure System. J. Comput. Chem. 1993, Vol.14, P. 1347-1363.

14. James J. P. Stewart, Stewart. Computational Chemistry, Colorado Springs, CO, USA, (2012).

15. Guirado-López R. A., Rincón M. E. Structural and optical properties of highly hydroxylated fullerenes: Stability of molecular domains on the C 60 surface. The Journal of Chemical Physics 2006. Vol. 125, P. 312-320. 
16. Сирота Т.В. Новый подход в исследовании реакции автоокисления адреналина: возможность полярографического опеределения активности супероксиддисмутазы и антиоксидантных свойств различных препаратов. Биомедицинская химия. 2012. T. 58 (1). C. 77-87. [Sirota T.V. A new approach in the study of adrenaline auto-oxidation reaction: the ability operedeleniya polarographic activity of superoxide dismutase and antioxidant properties of various drugs. Biomedical Chemistry 2012. Vol. 58(1), P. 77-87. (In Russ.)] 